\title{
PARAMETRIC STUDIES ON THE EFFECT OF FOUR TYPES OF FASTENER MODELING IN CHANNEL TYPE TENSION FITTING
}

\author{
Venkata Geetha Urimila Siddabathuni ${ }^{1}$, Srikanth Mekam $^{2}$, S S Subramanya \\ Sastry $^{3}$ \\ ${ }^{1}$ Team Leader, Engineering Aero \& Defence, Cyient Limited, Hyderabad \\ Geetha.Siddabathunidcyient.com \\ ${ }^{2}$ Team Leader, Engineering UTC, Cyient Limited, Hyderabad \\ srikanth.mekam@cyient.com \\ ${ }^{3}$ DGM (Tech), Engineering Aero \& Defence, Cyient Limited, Hyderabad \\ Subramanya.Sastry@cyient.com
}

\begin{abstract}
In this paper, some parametric studies on four types of Channel type tension fitting's fasteners' stiffness modeling is presented. Tension fittings are commonly classified into five types. They are Bathtub fitting, Channel fitting, Angle fitting, 'PI' fitting and Double angle fitting. Tension fittings are conservatively sized as their weight is usually small relative to their importance. In the previous studies, the channel fitting was considered to be fixed at all the fastener locations. Thus, the results obtained were conservative because the load was getting reacted at the first line of fasteners only. In order to study the effect of fastener's flexibility and hence the load flow inside the tension fitting two methods (Tate \& Swift) of fastener modeling were employed in the previous study. It observed that, the flexible boundary condition allow for a better load flow into the channel fitting as compared to the fixed boundary condition. In this study, fastener flexibility with two more methods (Grumann and Huth) is performed on the distribution of internal stresses in the channel fitting as compared to the fixed boundary conditions. Also comparison of previous results (Tate and Swift) is made with Grumann and Huth methods of modeling of fastener. Aluminum alloy 7050T7452 is selected for the study.
\end{abstract}

\section{KEYWORDS}

Tension Fittings, Flexibility of fasteners, Tate \& Swift, Grumann \& Huth method of modelling

\section{INTRODUCTION}

Tension fittings are one in which the bolt is loaded primarily in tension and they are used in the various applications like removable wing root joints of fighter wings, wing root joints at the four corners of the wing box, circumferential production joints on assemblies of fuselage sections, axial load transfer of the fuselage stringer by using tension bolt to go through major bulk head web rather than by cutting a large hole in the web and back-up fittings for support pylons, flap tracks etc., which have to go through wing box [1]. Channel fitting is a type of tension fitting. The cross section of the fitting resembles channel section. The web of the fitting is connected to walls of the fitting on both the sides. The channel fitting used in the present study is shown in Figure 1. 
International Journal of Recent advances in Mechanical Engineering (IJMECH) Vol.4, No.1, February 2015
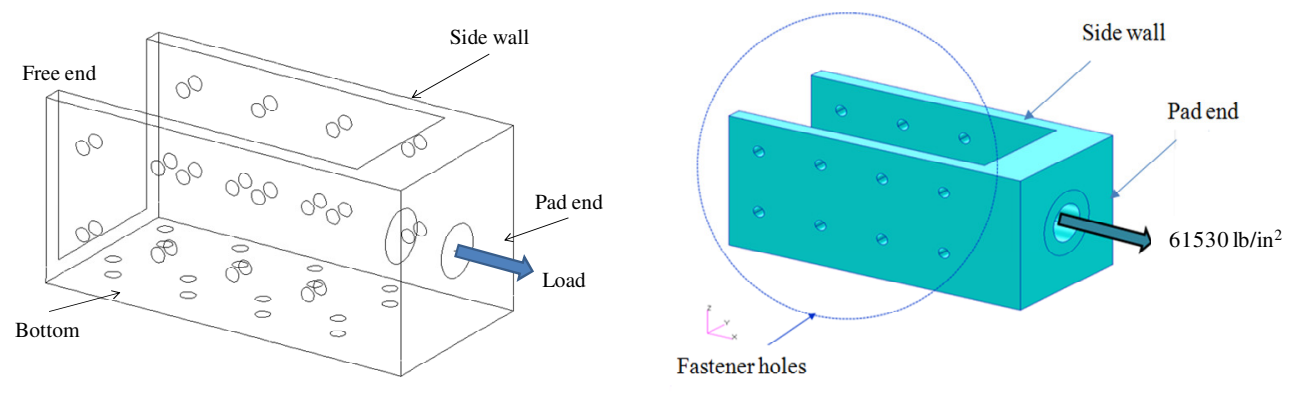

Figure 1. Channel Fitting geometry

\section{DIMENSIONS AND BOLT NUMBERING}

The dimensions of channel fitting are used for modeling in this study, material and loading on the fitting are shown below.

Thickness of Side wall 1 and $2=5.58 \mathrm{~mm}(0.22$ inch $)$

Thickness of Bottom wall $=4.32 \mathrm{~mm}(0.17$ inch $)$

Thickness of Backup structure $=5 \mathrm{~mm}(0.20$ inch $)$

Material: Aluminium Alloy (AA7050-T7452)

Ultimate $\mathrm{Load}=424.23 \mathrm{~N} / \mathrm{mm}^{2}\left(61530 \mathrm{lb} / \mathrm{in}^{2}\right)$

The following are the bolt numbering of the channel type fitting.
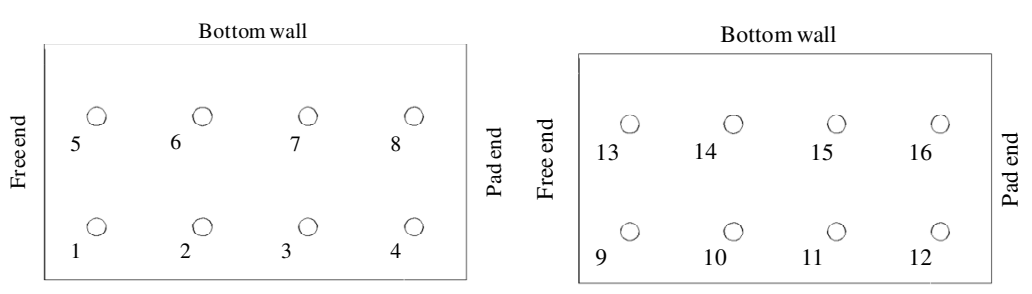

(A) Side wall 1

(B) Side wall 2

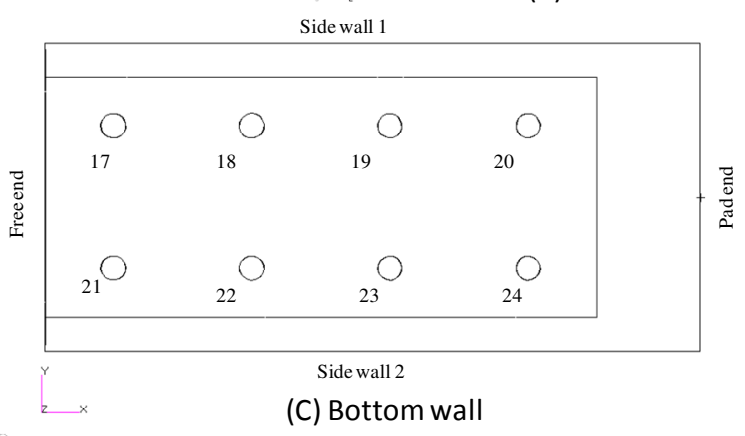

Figure 2. Bolt Numbering in Channel Fitting 


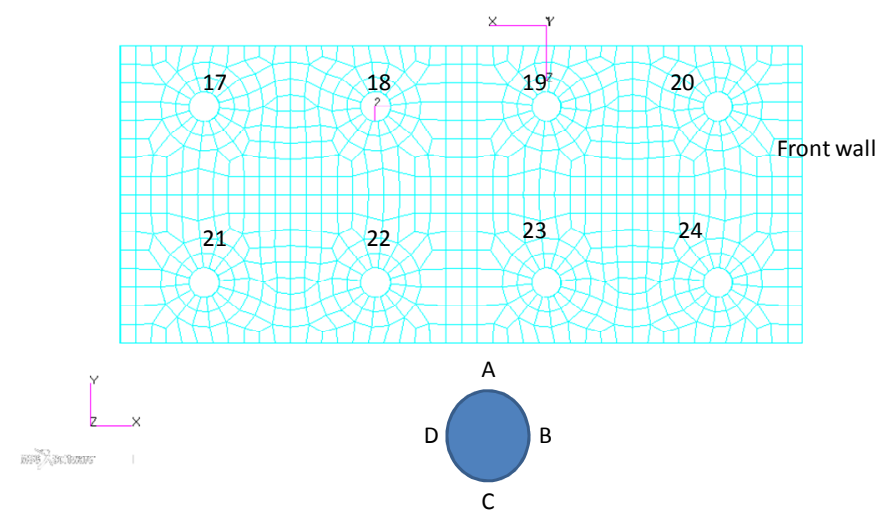

Figure 3. Description of Location A, B, C, D around the bolt hole

\section{FINITE ELEMENT MODELING}

The channel fitting is modelled using Hyper Mesh / Patran and analyzed using MSC/Nastran [2]. Appropriate local co-ordinate systems have been used in the various zones of channel fitting to define the orientation of bolts. The walls of channel fitting are modelled using CHEXA elements of the MSC/NASTRAN element library. The thicknesses of various zones are defined using the PSOLID card. The air loads are applied through PLOAD4 cards. The boundary conditions are simulated using the SPC cards and finally the materials properties are specified using the MAT1 cards.

Modeling bolts for three-dimensional finite element applications have, and still continue to raise questions. The limitations on model size sometimes make modeling of solid bolts impractical. Therefore, many analysts choose other analytical methods to model bolts.

Bolted joints are generally made up of the bolt group (head, stud, and nut) and the flange (top and bottom), as shown in Figure 4. Bolted connections are designed to hold two or more parts together to form an assembly.

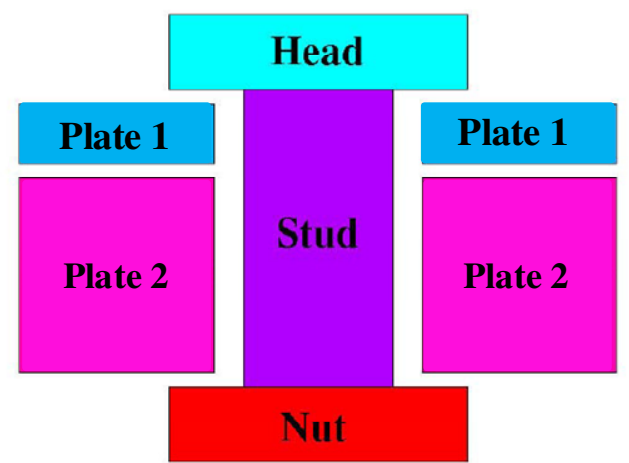

Figure 4. Block diagram of a typical Bolted Joint

In the current scenario, the stud of a bolt is modelled using spring element (CELAS). CELAS is a Scalar spring element that connects two degrees of freedom at two different grid points. They 
behave like simple extension/compression or rotational (e.g. clock) springs, carrying either force or moment loads. Forces result in translational (axial) displacement and moments result in rotational displacement. Translational stiffness as well as rotational stiffness can be defined separately. End A and End B are the both ends of the element, each node in the case of a twonodes CELAS2 element.

Since the walls of channels fitting are modelled with CHEXA element, RBE2 element is used to transfer load from CELAS element to the all CHEXA elements around the hole (Figure 5).

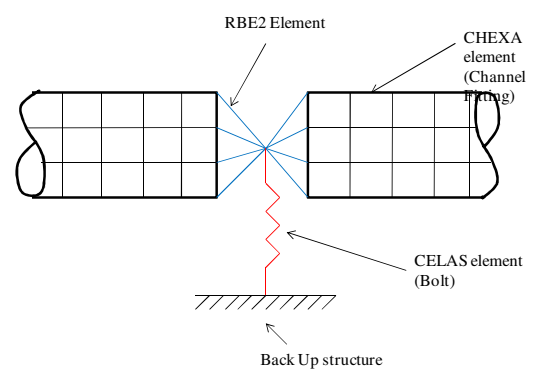

Figure 5. Idealization of Bolted Joint

The results are generated in the MSC/NASTRAN. The results are post-processed in PATRAN. Bolt loads at the various bolt locations are extracted using PATRAN. These free body loads are used for checking the number of bolts provided in the respective sections for adequacy.

\section{LOADS AND BOUNDARY CONDITIONS}

The channel fitting under study is assumed to be connected firmly to the backup structure using Titanium rivets (Ti-6AL-4V).

The loading on the fitting is assumed in the form of a pressure load at pad end (numerical value is given under Section 2). The load is assumed to be transferred through bolts.

\section{MATERIALS}

The channel fitting is made using the Aluminum alloy. Back up structure uses Aluminum alloy. Bolts are made up of Titanium alloy. The properties used for the analysis are typical as listed in MMPDS [3].

\section{ANALYSIS}

The fastener flexibility is a measure of the influence of fasteners (rivets, bolts, etc.) on the flexibility of the whole joints. It plays an important role when considering the factors influencing the strength level and fatigue life of an aircraft joint.

The flexibility can be defined as follows:

$$
\text { flexibility }(f)=\frac{1}{\text { Stiffness }(K)}=\frac{\Delta l}{F}
$$


in which $\mathrm{F}$ refers to the external force and $\Delta \mathrm{l}$ to the deflection of the joint due to the fastening (in other words: the deflection of the joint around the fastener excluding the normal extension of the sheet material).

In terms of load transfer and deformation, the fasteners stiffness (flexibility) determines the way load is transferred from one component to another, and choosing the right value of stiffness is an important factor in the results of a joint analysis (Figure 6).

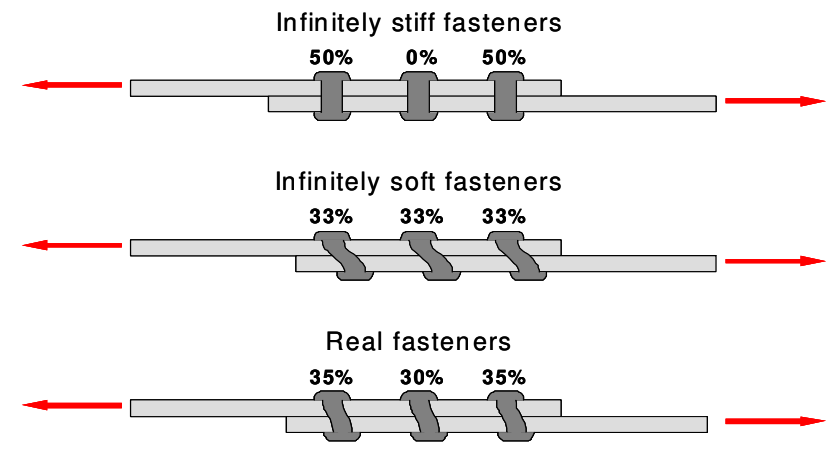

Figure 6. Load transfer in Bolted Joint

The basic approach to model a flexible joint is representing the fasteners and the fastened components by springs, with the corresponding flexibility as follows.

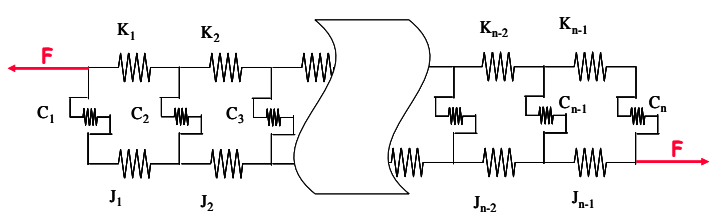

Figure 7. Block diagram of flexibility of fasteners

With

$\mathrm{K}_{\mathrm{i}}=$ Stiffness (flexibility) inter fastener upper plate

$\mathrm{J}_{\mathrm{i}}=$ Stiffness (flexibility) inter fastener lower plate

$\mathrm{C}_{\mathrm{i}}=$ Fasteners stiffness (flexibility)

In that way some equations of compatibility must be satisfied by the system plates-fasteners with coherent deformations. There are several formulations for the fasteners flexibility. The most important existing and recognized formulas are, with the parameters defined as follows,

$$
\begin{array}{ll}
\text { Configuration: } & \mathrm{d}=\text { Hole diameter } \\
& \mathrm{t}=\text { Plate thickness } \\
& \mathrm{n}=\text { Single or double shear switch } \\
\text { Material: } & \mathrm{E}=\text { Young's modulus } \\
& \mathrm{v}=\text { Poisson ratio } \\
\text { Indices: } & 1=\text { Plate } 1 \text { (central one in double shear) } \\
& 2=\text { Plate } 2 \text { (outer ones in double shear) } \\
& \mathrm{f}=\text { fastener }
\end{array}
$$


- Swift (Douglas)

$$
f=\frac{5}{d E_{f}}+0.8\left(\frac{1}{t_{1} E_{1}}+\frac{1}{t_{2} E_{2}}\right)
$$

- $\quad$ Tate \& Rosenfeld

$$
\begin{gathered}
f=\frac{1}{E_{f} t_{1}}+\frac{1}{E_{f} t_{2}}+\frac{1}{E_{1} t_{1}}+\frac{1}{E_{2} t_{2}}+ \\
+\frac{32}{9 E_{f} \pi d^{2}} \cdot\left(1+\nu_{f}\right)\left(t_{1}+t_{2}\right)+\frac{8}{5 E_{f} \pi d^{4}} \cdot\left(t_{1}^{3}+5 t_{1}^{2} t_{2}+5 t_{1} t_{2}^{2}+t_{2}^{3}\right)
\end{gathered}
$$

- Huth

$$
f=\left(\frac{t_{1}+t_{2}}{2 d}\right)^{a} \frac{b}{n}\left(\frac{1}{t_{1} E_{1}}+\frac{1}{n t_{2} E_{2}}+\frac{1}{2 t_{1} E_{f}}+\frac{1}{2 n t_{2} E_{f}}\right)
$$

$a$ and $b$ depends on the type of joint, $n=1$ for single shear and 2 for double shear

\begin{tabular}{c|cc}
\hline Type & $a$ & $b$ \\
\hline bolted metallic & $2 / 3$ & 3.0 \\
riveted metallic & $2 / 5$ & 2.2 \\
bolted graphite/epoxy & $2 / 3$ & 4.2 \\
\hline
\end{tabular}

- Grumman

$$
f=\frac{\left(t_{1}+t_{2}\right)^{2}}{E_{f} d^{3}}+3.7\left(\frac{1}{E_{1} t_{1}}+\frac{1}{E_{2} t_{2}}\right)
$$

\section{RESULTS AND DISCUSSIONS:}

The results are presented for the following five boundary conditions.

1. Fixed

2. Tate \& Rosenfield

3. Swift

4. Grumann

5. Huth

The internal stresses are compared for the following four types of stresses.

1. Major Principal Stress

2. Minor Principal Stress

3. Maximum Shear Stress

4. von-Mises Stress

\subsection{Major Principal Stress}

Major principal stress variation in the channel fitting is presented in this paragraph. The aim of the exercise is to identify the most suitable bolt flexibility model that makes the full channel fitting useable (fully stressed design). It is observed that the load is getting transferred from pad end to the free end (Figure 1) by proper modeling of the flexibility of bolts when compared to fixed condition to various degrees in the 4 bolt flexibility models. Distribution of major principal stress in the channel fitting using various bolt flexibility models is shown in Figure 8. 


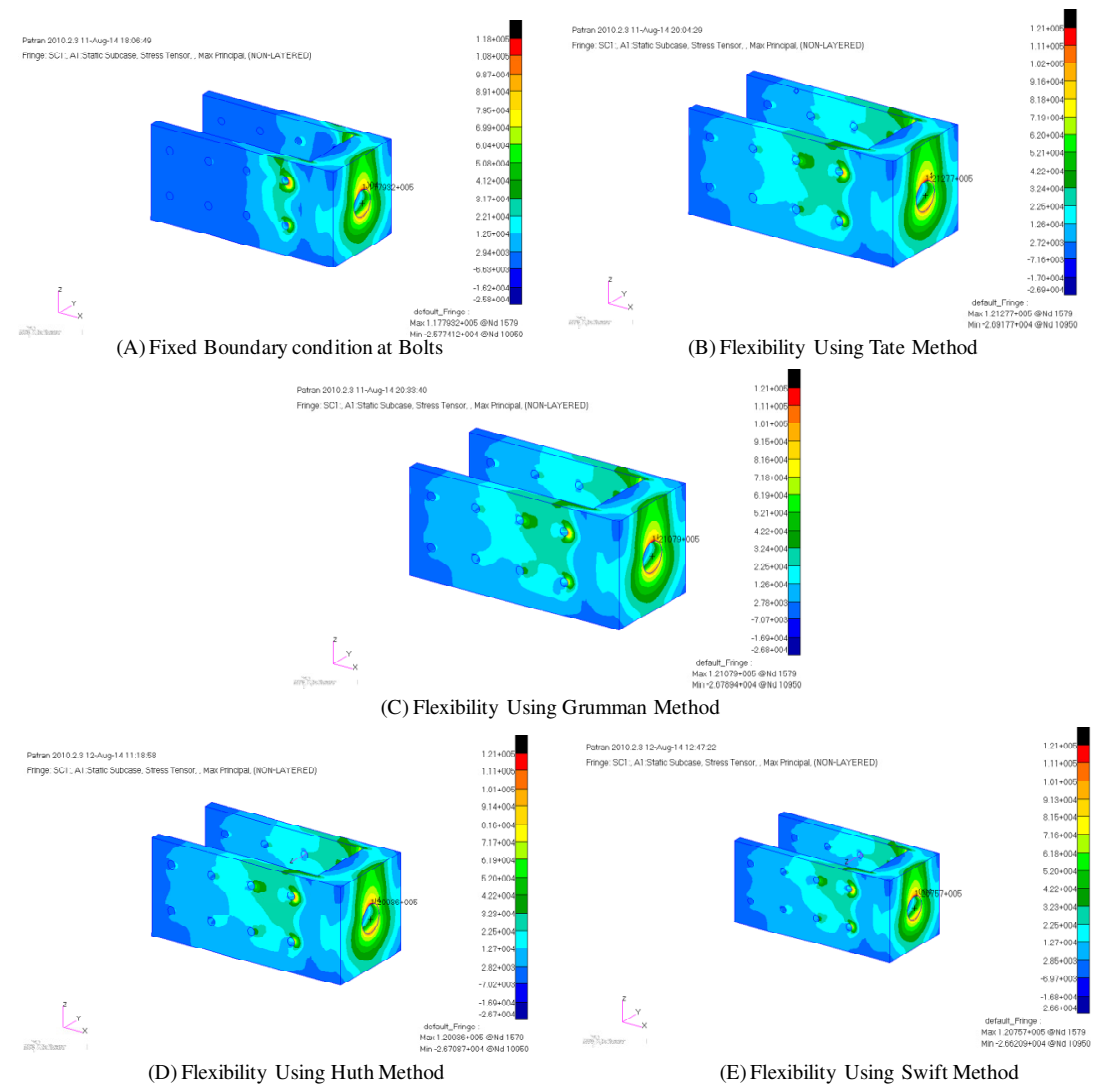

Figure 8. Distribution of Major Principal Stress

A study of stress at each bolt location is made to understand best stress flow under the given loading condition. It is observed that for Bolt 24 (Figure 3), The Major principal stress at location ' $\mathrm{A}$ ' (Figure 9) in the fixed boundary condition model is observed to be $122.97 \mathrm{MPa}$ (17835.74 $\mathrm{lb} / \mathrm{in}^{2}$ ). In Tate's method of modeling for fasteners, it is observer that the Maximum Principal stress obtained is $90.15 \mathrm{MPa}(73.31 \%$ of $122.97 \mathrm{MPa})$. In Boeing's method of modeling for fasteners, it is observed that the Maximum Principal stress obtained is $66.93 \mathrm{MPa}(54.43 \%$ of 122.97 MPa). In Grumman's method of modeling for fasteners, it is observed that the Maximum Principal stress obtained is $78.17 \mathrm{MPa}(63.57 \%$ of $122.97 \mathrm{MPa})$. In Huth's method of modeling for fasteners, it is observed that the Maximum Principal stress obtained is $71.89 \mathrm{MPa}(58.47 \%$ of 122.97 MPa). In Swift's method of modeling for fasteners, it is observed that the Maximum Principal stress obtained is $67.30 \mathrm{MPa}(54.73 \%$ of $122.97 \mathrm{MPa})$. Similarly, the percentage variation of the major principal stress at 24A, 23A, 22A and 21A are presented in Figure 9.

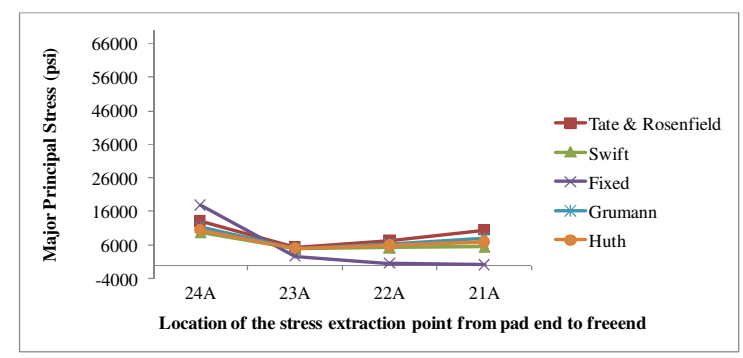

(A) 


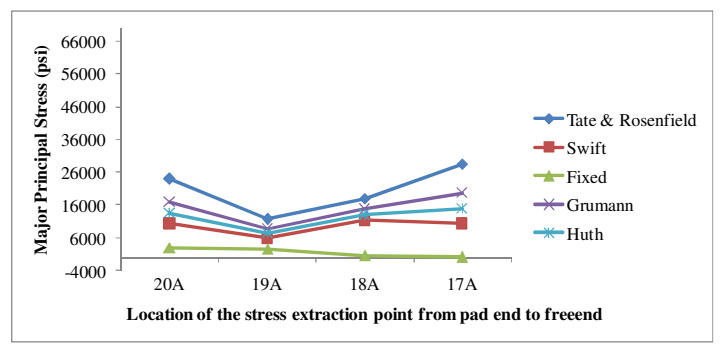

(B)

Figure 9. Variation of Major Principal Stress of Bottom wall

\subsection{Minor Principal Stress}

Minor principal stress variation in the channel fitting is studied. It is observed that the load is getting transferred from pad end to the free end (Figure 1) by proper modeling of the flexibility of bolts when compared to fixed condition to various degrees in the different bolt flexibility models. Distribution of minor principal stress in the channel fitting using various bolt flexibility models is shown in Figure 10.

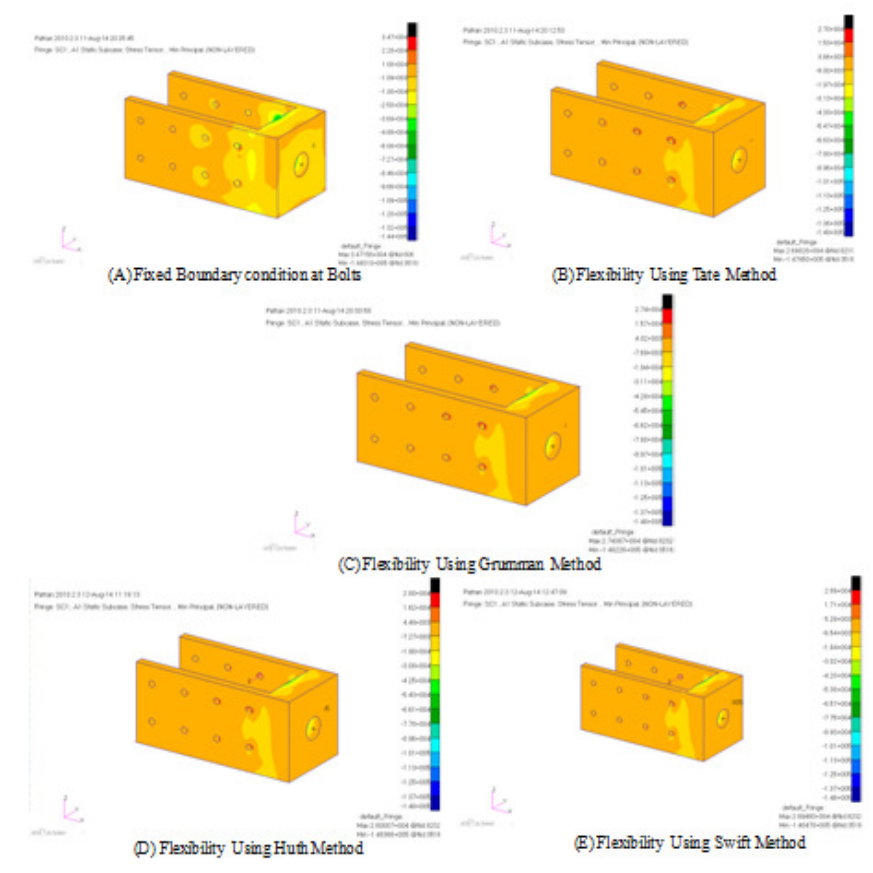

Figure 10. Distribution of Minor Principal Stress

A study of stress at each bolt location is made to understand best stress flow under the given loading condition. It is observed that for Bolt 24 (Figure 3), The Minor Principal stress at location 'A' (Figure 11) in the fixed boundary condition model is observed to be $-136.63 \mathrm{MPa}$ ($\left.19816.931 \mathrm{~b} / \mathrm{in}^{2}\right)$. In Tate's method of modeling for fasteners, it is observer that the Minor principal stress obtained is $-141.71 \mathrm{MPa}(103.72 \%$ of $-136.63 \mathrm{MPa})$. In Boeing's method of modeling for fasteners, it is observed that the Minor principal stress obtained is $-151.88 \mathrm{MPa}$ (111.16\% of $-136.63 \mathrm{MPa})$. In Grumman's method of modeling for fasteners, it is observed that the Minor principal stress obtained is $-96.84 \mathrm{MPa}(70.88 \%$ of $-136.63 \mathrm{MPa})$. In Huth's method of modeling for fasteners, it is observed that the Minor principal stress obtained is $-137.26 \mathrm{MPa}$ 
(100.46\% of $-136.63 \mathrm{MPa})$. In Swift's method of modeling for fasteners, it is observed that the Minor principal stress obtained is $-145.40 \mathrm{MPa}(106.42 \%$ of $-136.63 \mathrm{MPa})$. Similarly, the percentage variation of the Minor principal stress at 24A, 23A, 22A and $21 \mathrm{~A}$ are presented in Figure 11.

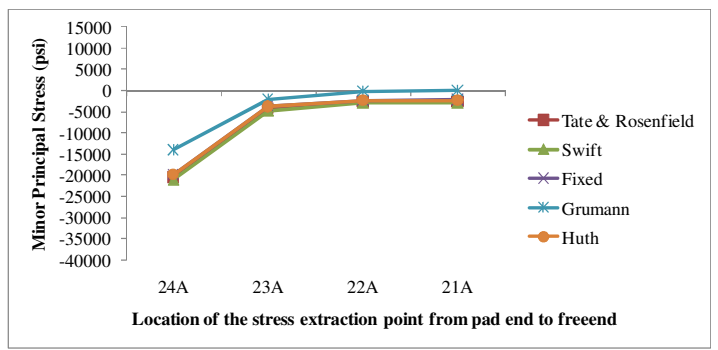

(A)

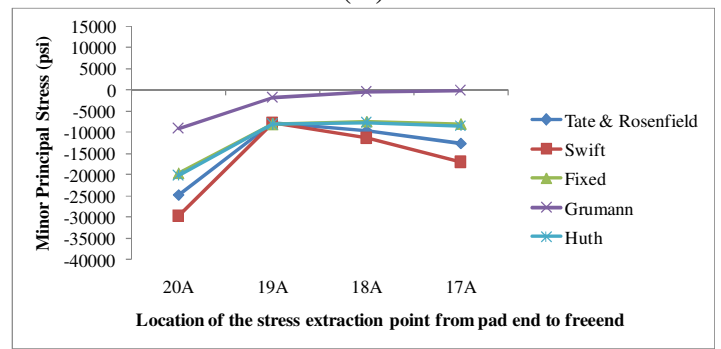

(B)

Figure 11. Variation of Minor Principal Stress of Bottom wall

\subsection{Maximum Shear Stress}

Maximum Shear stress variation in the channel fitting is studied. It is observed that the load is getting transferred from pad end to the free end (Figure 1) by proper modeling of the flexibility of bolts when compared to fixed condition to various degrees in the different bolt flexibility models. Distribution of Maximum Shear Stress in the channel fitting using various bolt flexibility models is shown in Figure 12. 


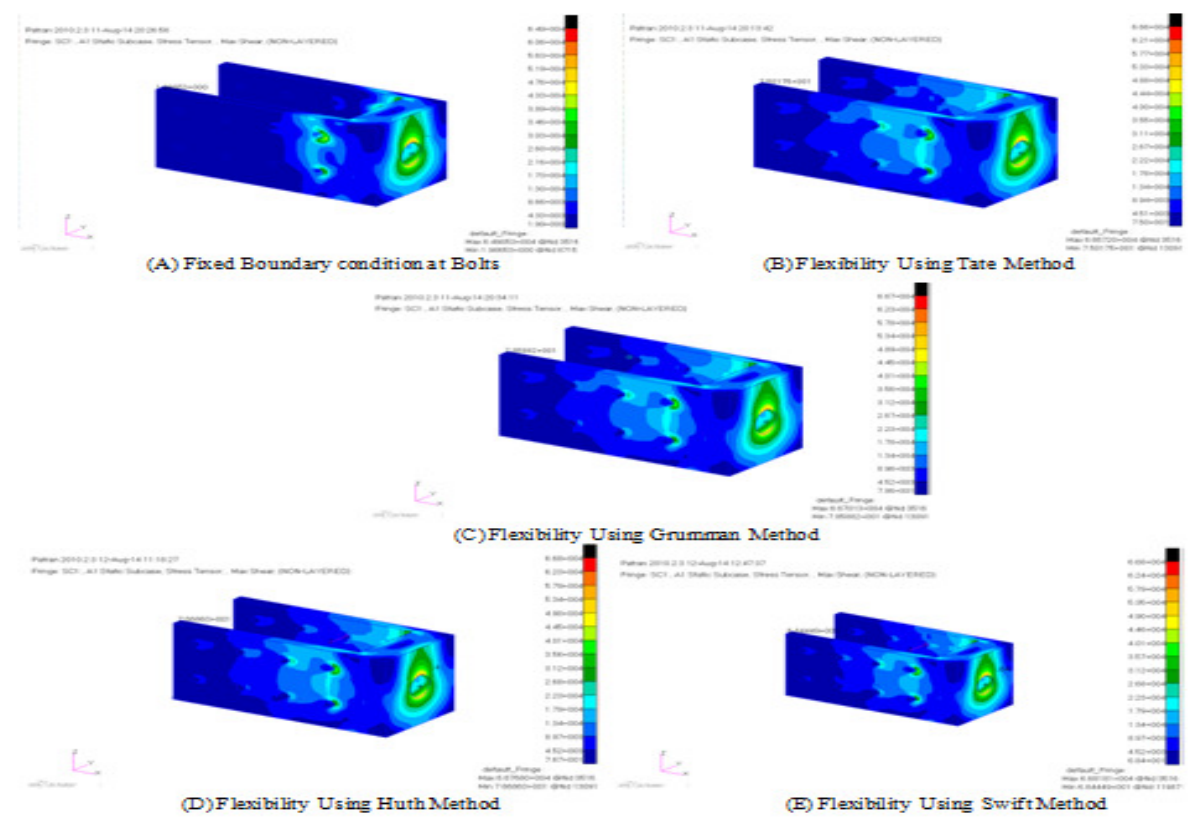

Figure 12. Distribution of Maximum Shear stress

A study of stress at each bolt location is made to understand best stress flow under the given loading condition. It is observed that for Bolt 24 (Figure 3), The Maximum Shear Stress at location 'A' (Figure 13) in the fixed boundary condition model is observed to be $101.78 \mathrm{MPa}$ $\left(14762.481 \mathrm{~b} / \mathrm{in}^{2}\right)$. In Tate's method of modeling for fasteners, it is observer that the Maximum Shear Stress obtained is 106.80MPa (104.93\% of 101.78MPa). In Boeing's method of modeling for fasteners, it is observed that the Maximum Shear Stress obtained is 121.01MPa $(118.90 \%$ of 101.78MPa). In Grumman's method of modeling for fasteners, it is observed that the Maximum Shear Stress obtained is $109.91 \mathrm{MPa}(107.98 \%$ of $101.78 \mathrm{MPa})$. In Huth's method of modeling for fasteners, it is observed that the Maximum Shear Stress obtained is $102.28 \mathrm{MPa}(100.49 \%$ of 101.78MPa). In Swift's method of modeling for fasteners, it is observed that the Maximum Shear Stress obtained is $111.78 \mathrm{MPa}(109.83 \%$ of $101.78 \mathrm{MPa})$. Similarly, the percentage variation of the Maximum Shear Stress at 24A, 23A, 22A and 21 A are presented in Figure 13.

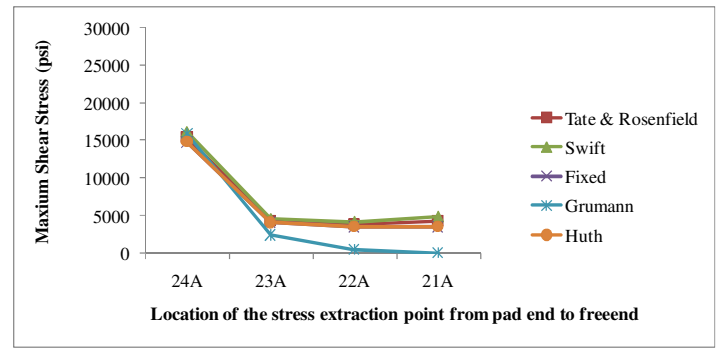

(A) 


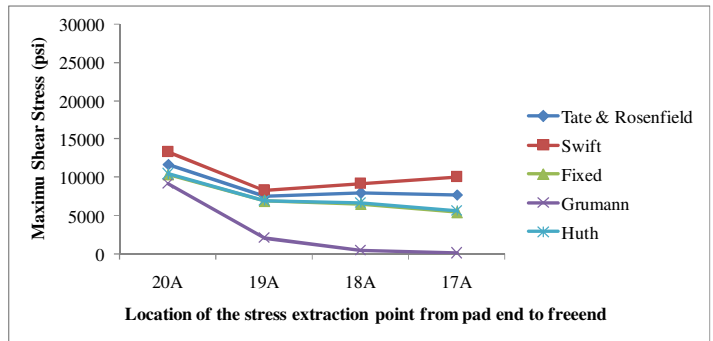

(B)

Figure 13. Variation of Maximum Shear stress of Bottom wall

\section{4 von-Mises Stress}

von-Mises stress variation in the channel fitting is studied. It is observed that the load is getting transferred from pad end to the free end (Figure 1) by proper modeling of the flexibility of bolts when compared to fixed condition to various degrees in the different bolt flexibility models. Distribution of von-Mises stress in the channel fitting using various bolt flexibility models is shown in Figure 14.

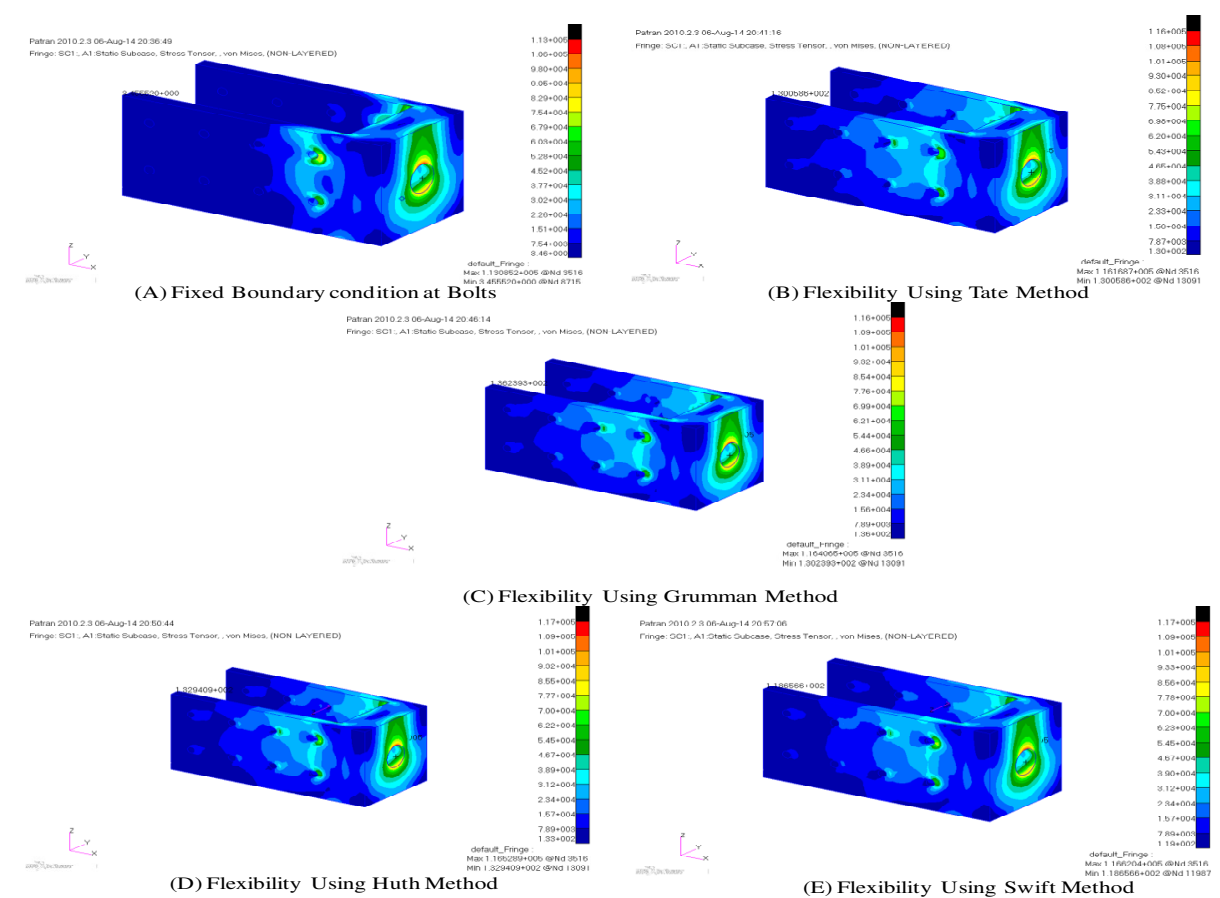

Figure 14. Distribution of von-Mises stress

A study of stress at each bolt location is made to understand best stress flow under the given loading condition. It is observed that for Bolt 24 (Figure 3), the von-Mises stress at location 'A' (Figure 15) in the fixed boundary condition model is observed to be $177.01 \mathrm{MPa}$ $\left(25673.42 \mathrm{lb} / \mathrm{in}^{2}\right)$. In Tate's method of modeling for fasteners, it is observer that the von-Mises stress obtained is $185.54 \mathrm{MPa}(104.82 \%$ of $177.01 \mathrm{MPa})$. In Boeing's method of modeling for fasteners, it is observed that the von-Mises stress obtained is $209.79 \mathrm{MPa}(118.52 \%$ of 177.01MPa). In Grumman's method of modeling for fasteners, it is observed that the von-Mises stress obtained is $190.76 \mathrm{MPa}(107.77 \%$ of $177.01 \mathrm{MPa})$. In Huth's method of modeling for fasteners, it is observed that the von-Mises stress obtained is $177.87 \mathrm{MPa}(100.49 \%$ of 
177.01MPa). In Swift's method of modeling for fasteners, it is observed that the von-Mises stress obtained is $194.01 \mathrm{MPa}(109.60 \%$ of $177.01 \mathrm{MPa})$. Similarly, the percentage variation of the vonMises stress at 21A, 22A, 23A and 24A are presented in Figure 15.

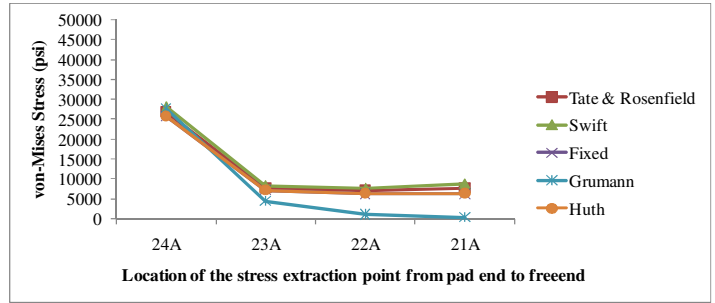

(A)

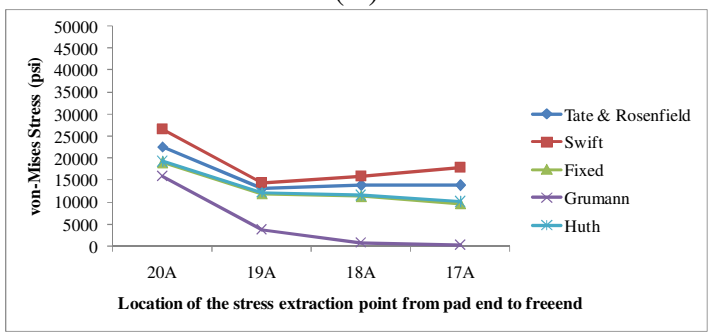

(B)

Figure 15. Variation of von-Mises stress of Bottom wall

\section{CONCLUSIONS}

In this study, a typical channel fitting is modelled using 4 types of fastener flexibility models. The results are compared and studied with the fixed boundary conditions for the variation of major principal, minor principal, maximum shear and von-Mises stresses in the various parts of the channel fitting. The following conclusions are drawn from the study.

1. The flexible boundary conditions allow for a better load flow into the channel fitting as compared to the fixed boundary condition.

2. The flexible boundary conditions modeling helps in bolts in a more realistic modeling as compared to the fixed boundary conditions.

3. The Tate's method of flexibility calculations models the bolts in a better way (as determined by the percentage of stress flow) the flow of load from the load applications ( $p a d$ end) end of the fitting to the free end of the channel fitting.

4. The deflection pattern is comparable in both bolt flexibility models.

5. Capturing of stress pattern is comparable in both bolt flexibility models.

\section{REFERENCES}

[1] Niu, Airframe stress analysis and sizing, Second edition 1999.

[2] MSC Corporation, MSC Nastran Quick Reference Guide, 2007 r1.

[3] MIL-HDBK-5H, Change Notice 1, 1 October 2001. 


\section{ACKNOWLEDGEMENT}

We sincerely thank and acknowledge the support and encouragement provided by Mr. Hemant Modak, VP (ENGG-AERO \& DEFENCE) \& Mr. Sridhar Lomite (Head of GKN CoE) of Cyient Limited in bringing out this work in the form of a technical paper. Special thanks to all the members of the team who have contributed immensely to the successful execution of the project.

\section{Authors}

\section{Mrs. Venkata Geetha Urimila Siddabathuni}

Geetha completed her B.Tech (Mechanical Engineering) in 2007 from Nagarjuna University. She joined Cyient Limited (formerly Infotech Enterprises Limited) in 2007 as Stress Engineer. Geetha has been involved in stress analysis for various components of wing structure in A400M, A350, A320 and A380 programs. Currently, she holds the position of Team Leader for concessions on various programs such as A350, Boeing, Bombardier, Trent and Dassault. Her main interest lies in the stress analysis for the various components. She has published a paper on "Numerical Analysis of Adhesive Bonded Scarf Repairs to Thick Composite Aircraft Structure" in international conference.

\section{Mr. Srikanth Mekam}

Srikanth Mekam completed his B.E (Mechanical Engineering) in 2007 from Osmania University. He joined Cyient Limited (formerly Infotech Enterprises Limited) in 2007 as Repair Development Engineer. Srikanth has been involved in developing repair techniques for various engine components of PW4000, GP7000, PW6000, JT8D, JT9D and PW1500G engines. Currently, he holds the position of Team Leader for repair development on PW1500G engine model. He is pursuing his M.Tech in Aeronautical Engineering from JNTU.

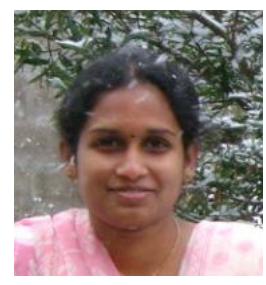

\section{Mr. Subramanya Sastry S S}

Subramanya Sastry has 28 years of experience in Aerospace domain in the areas of Composite/Metallic airframe design and development, manufacturing, assembly and testing processes in National Aerospace Laboratories, Bangalore in HANSA, LCA and SARAS aircraft programs - indigenized Civil and Military aircraft design and development programs. He has participated in the design and analysis activities of A380 flap track fairings, A400M spar check stress activities, optimization of A350 floor panels, A350 fuselage frame sizing, A350 MBN for IFTE and Boeing 787 Dreamliner Translating Sleeve analysis.

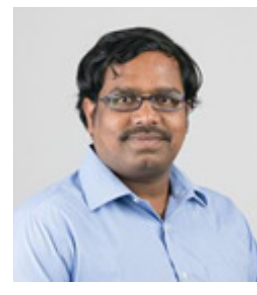

He is presently working with Cyient Limited as an Deputy General Manager (Technical). Currently he is involved in the A400M Spar Checkstress Stress Dossier Preparation for Certification. He conducts workshops and seminars on composites and aircraft engineering topics regularly for all the enthusiastic engineers.

He is having 26 publications in International/National Journals and conferences. He is Honorary Chairman for NAFEMS India Composite Working Group, member for NAFEMS India Council and Technical Expert Member at NAFEMS Panel on Certification for CAE professionals.

\section{Fellowship / Membership of Professional bodies}

- Fellow of the Institution of Engineers (India, F1139645, 2009),

- Fellow of the Indian Institution of Production Engineers (Regn.No.S/LF/6368, 2013)

- Life Member, Aeronautical Society of India (M17037)

- Life Member, Indian Society of Advancement of Material and Process Engineering (ISAMPE, L341)

- $\quad$ Life Member, Engineering Design and Analysis Forum (EDAF/2008/ED77) 